-

\title{
Achalasia Cardia: A Rare Cause Of Primary Oesophageal Immobility
}

\author{
Polanki Rajarajeswari® ${ }^{1}$, Anakala Hemanth Reddy $\odot^{1}$, C. Bhargav Reddy $\odot^{2}$, \\ RE. Ugandar $\odot^{3}$, C. Madhusudhana Chetty $\odot^{3}$ \\ Department of Pharmacy Practice, Santhiram College of Pharmacy, Nandyal, AP, India
}

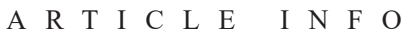

Article history:

Received 23 February 2021

Accepted 27 February 2021

Available online 18 March 2021

Keywords:

Achalasia cardia

Oesophagus

Neurodegenerative disorder

Dysphagia

Heller's myotomy

\section{A $B \quad S \quad T \quad R \quad A \quad C \quad T$}

Achalasia cardia is a rare chronic neurodegenerative disorder of the oesophagus which causes progressive delay in contractility of lower oesophageal muscles during swallowing leading to regurgitation of food contents and fluids in advanced stages within the region of oesophagus. The underlying aetiology include autoimmune disorder, nervous degeneration due to loss of inhibitory ganglion in myenteric plexus of oesophagus, presence of inhibitory neurotransmitters such as nitric oxide and its receptors in lower oesophagus. Achalasia is characterised by oesophageal nonperistaltic contraction and incomplete relaxation of lower oesophageal sphincter. The common symptoms are dysphagia, regurgitation, and heartburn. Case report discussed below is of a 38 years old female patient presented with dysphagia for two years. The symptoms of which worsened for one month along with vomiting after consumption of food.

(C) 2020, Rajarajeswari P, Hemanth Reddy A, Bhargav Reddy C, Ugandar RE, Madhusudhana Chetty C, This is an openaccess article distributed under the terms of the Creative Commons Attribution 4.0 International License, which permits unrestricted use, distribution and reproduction in any medium, provided the original author and source are credited.

\section{Introduction}

Achalasia is defined as the failure of organised peristalsis in oesophagus and failure of relaxation at the level of lower oesophageal sphincter. Achalasia is equally common in both genders. Most commonly diagnosed between in 40 to 60 years of age, Achalasia can present in any age group [1]. Asian data from korea showed incidence of 0.4 per 100000 population per year and prevalence of 6.3 per 100000 population per year [2]. Achalasia cardia is a primary motility disorder of oesophagus due to loss or reduction of ganglionic cells in the auerbach's plexus. Hereditary, degenerative, autoimmune and infectious factors are most possible causes of Achalasia [3,4]. Autoimmune progressive degeneration of ganglion cells in the oesophageal myenteric plexus in genetically susceptible individuals (human leukocyte antigen-DQ variants DQA1"0103 and DQB1*0603) are the most probable pathogenetic event leading to Achalasia [5]. The diagnosis of Achalasia should be suspected if any one complains of progressive dysphasia for solid and liquid with regurgitation of food and saliva. The clinical suspicion should be established by barium oesophagram [6]. All patients should undergo upper gastro intestinal endoscopy to exclude pseudoachalasia arising from a tumour at gastro-oesophageal junction [7]. Upper GI endoscopy and timed barium oesphagogram are the primary investigations to rule out mechanical obstruction. High resolution manometry (HRM) is

\footnotetext{
Corresponding author.

P. Rajarajeswari, Pharm D Intern, Santhiram College of

Pharmacy, Nandyal

E-mail address: ambikaram3@gmail.com
}

diagnostic and helps to classify Achalasia [8]. There is no cure for achalasia. The goal of treatment is relief of patient symptoms and to improve oesophageal emptying. Achalasia treatment focuses on relaxing or stretching open the lower oesophageal spinchter so that food and liquid can move more easily through digestive tract. Non surgical treatments include pneumatic dilation, Botox (botulinum toxin A), medications like muscle relaxants. The most two effective surgical treatments are graded heller's myotomy and per oral endoscopic myotomy either or laparoscopic procedure [9].

Here is a case report of achalasia cardia which underwent Heller's myotomy and shows better postoperative symptomatic improvement.

\section{Case Study}

A female patient of age 38 years old was admitted in surgical gastro department with the chief complaints of dysphagia for 2 years and regurgitation of food and saliva after consumption for one month. The patient had loss of appetite and weight loss for 3 months. There was no history of haemoptysis. She had been receiving symptomatic treatment at her native place but not relieved.

Physical examination reveals no abnormality. Her vitals were recorded temperature was $98.3^{\circ} \mathrm{F}$, heart rate was $80 \mathrm{per} / \mathrm{min}$, blood pressure $110 / 70 \mathrm{mmHG}$, respiratory rate is $18 \mathrm{per} / \mathrm{min}$ and $\mathrm{SpO}_{2}$ at room air was $99 \%$. On general examination no icterus, lymphadenopathy, or oedema was observed. Barium oesophagram was done and showed marked dilatation of oesophagus proximal to obstruction at the lower end. The ultrasound scan of abdomen shows grade I hepatic steatosis. On laboratory investigations shows decreased haemoglobin i.e., 6.8. As the patient is anaemic she was underwent blood transfusion with 2 units 


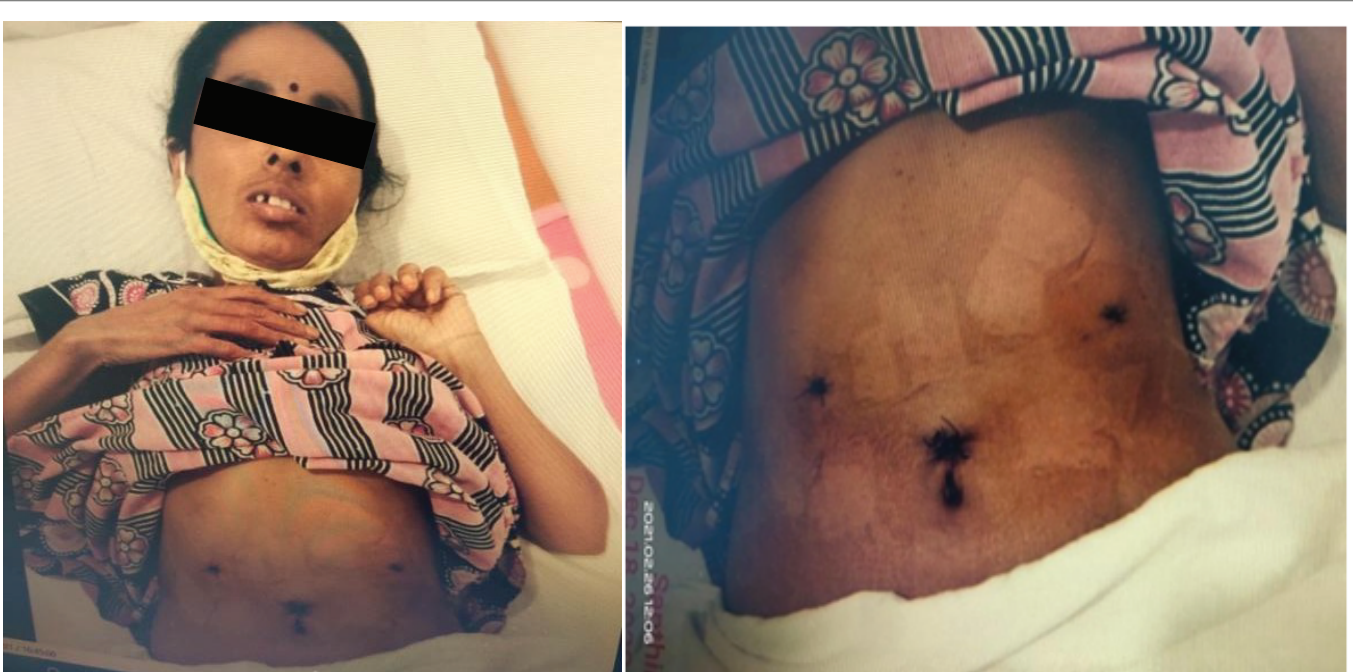

Figure: Laproscopic hellers myotomy + Anterior fundoplication

of packed red blood cells. On CVS examination S1 and S2 sounds are present. Based on above parameters the patient was suspected as a case of achalasia cardia.

The patient was treated by Heller's myotmy procedure through the laparoscopic approach. Under general anaesthesia ports inserted after creating pneumoperitonium, liver retracted. Posterior left crus

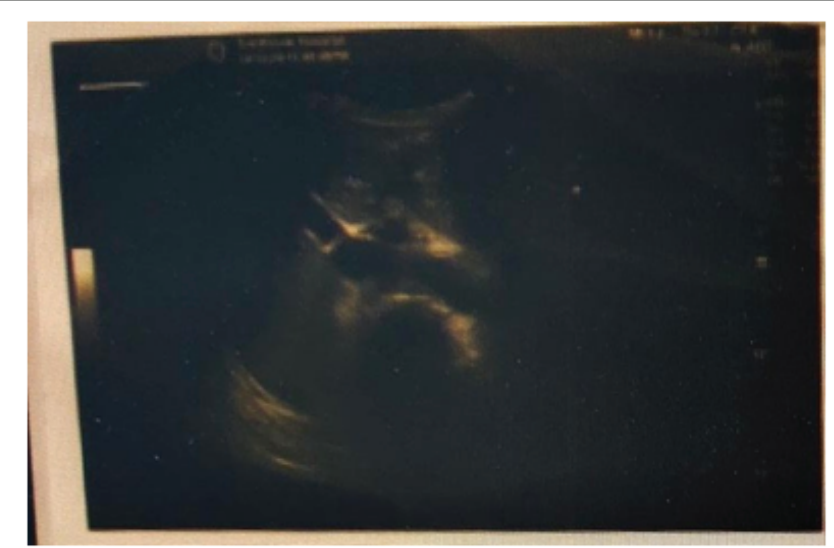

Figure: Ultra sound scan of post op abdomen

exposed, gastric fundus mobilised dividing the short gastric arteries, anterior phrenoesophagial ligamentincised, right crus base dissected. Mobilise the anterior mediastinal attachment of the oesophagus. Myotomy performed with electrocautery, noting to spare the anterior and sub mucosa left intact, distal oesophagus checked for integrity and lack of spasm. Create wrap of fundus around oesophagus anterior dorwrap created and anchoring stitches taken including bites of oesophagus, haemostasis achieved, drains placed near dissection site, ports closed.

The postoperative management includes antibiotic (cefperazone + sulbactum $1.5 \mathrm{gm}$, metranidazole $400 \mathrm{mg}$ ), antacids (pantoprazole 40 $\mathrm{mg}$ ), antiemitics (ondanserton $4 \mathrm{mg}$ ) analgesics (tramadol $100 \mathrm{mg}$ ).

Her post operative recovery was good. The patient was discharged from hospital after 10 days of surgery and advised her to follow up after one month.

\section{Discussion}

Achalasia of the oesophagus was first described by Hannary in 1933. Mikulica explained it is being due to spasm of cardiac sphincter but dissection showed no anatomical sphincter at this point. The disease is common in middle life but can occur at any age [9]. The onset of disease is insidious.

The most common symptoms are initial dysphagia to solid and liquid, regurgitation and chest pain. Mainly dysphagia present only to solids in about 70 to $97 \%$ patients. In later stages it is presented to both solids and liquids. Dysphagia is the cardinal symptom in patients with achalasia and is present in more than $90 \%$ of the patients $[10,11]$. Regurgitation, weight loss, chest pain or discomforts are other common symptoms [10,11]. Most of the patients are symptomatic.

A barium swallow oesophagus is the single best diagnostic study when Achalasia cardia is suspected by absence of primary peristalsis and smooth, tapered narrowing of the distal oesophagus caused by incomplete relaxation of the lower oesophageal sphincter [12] .

Among motility disorder only Achalasia cardia responds well to the treatment. The two main methods are forceful dilatation of cardia and Heller's myotomy either open or laparoscopic surgery. Surgical myotomy involves a single anteriorly placed incision made through the serous layer, longitudinal and circular muscle fibers of oesophagus up to mucosa [13]. The major complication of this procedure is gastro-oesophageal reflux.

In this case a 38 years old female presented with dysphagia for 2 years and the symptoms got worsen from one month. After admission the patient underwent Heller's myotomy through laparoscopically for Achalasia cardia.

\section{Conclusion}

Achalasia cardia is a rare disorder which affects the oesophageal motility. Patient suffering from this disorder have imbalance of excitatory and inhibitory neurotransmission which results in non relaxing lower oesophagus causes motor dysphagia. Now a days it can be successfully treated with the surgical procedures such as forceful dilation of cardia and heller's myotomy. In this case the patient was treated by heller's myotomy in laparoscopic approach. Early diagnosis and management of achalasia cardia leads to better prognosis and good quality of life.

\section{Acknowledgement}

We would like to express our special thanks of gratitude to Dr.C.Praneeth and Dr.P.Raghu Sree Charan, department of surgical gastroenterology who provided insight and expertise that greatly assisted us with the case report.

\section{Conflict of interest}

The authors declared no conflict of interests with respect to authorship and publication of this case.

\section{References}

1. Jung HK, et al. 2019 Seoul consensus on esophageal achalasia guidelines. J Neuro- gastroenterol Motil. 2020;26(2):180-203.

2. Kim E, et al. Achalasia in Korea: an epidemiologic study using a national healthcare database. J Korean Med Sci. 2014;29(4):576-80. 


\section{CASE STUDY - OPEN ACCESS}

Rajarajeswari P et al. / Journal of Gastrectomy Lymphadenectomy Splenectomy Cholecystectomy

3. Vaezi MF, Richter JE. Current therapies for achalasia: comparison and efficacy. J Clin Gastroenterol. 1998;27:21-35.

4. Mirgisson SJE. Achalasia: What's new in diagnosis and treatment? Dig Dis. 1997;15:1-27.

5. Ruiz-de-Leon A et al. Myenteric antiplexus antibodies and Class II HLA in achalasia. Dig Dis Sci. 2002;47:15-19.

6. Carlos A P, Lawrence W. Oesphagus and diaphram. Current surgical diagnosis and treatment. Edition 10. 411-438.

7. Michael MF, Richter JE. Diagnosis and management of achalasia. Am J Gastro. 1999;94:3406-3412.

8. Pandolfino JE, et al. Achalasia: a new clinically relevant classification by high-resolution manometry. Gastroenterol. 2008;135:1526-33.
9. Thomas R J, Sen S, Zachaian N. Achalasia cardia in infancy and childhood: An Indian experience. J R Coll Surg. 1998;43:103-104.

10. Muralidharan S, Jairaj PS, Periyanayagam WJ, John S. Achalasia cardia: A review of 100 cases. Aust NZ J Surg. 1978;48:167-70.

11. Mirchandani LV, Joshi JM. Achalasia cardia: Perplexing chest radiographs. J Assoc Physicans India. 1995;43:721-22.

12. Haubrich WS, Schaffer F, Berk JE. Bockus Gastroenterology. Philadelphia: W.B. Saunders and Co.; 1995:422-36.

13. Ott DJ. Motility disorders. In: Gore RM, Levine MS, Laufer I, eds. Textbook of Gastrointestinal Radiology. Philadelphia: Saunders. 1994:346-359.

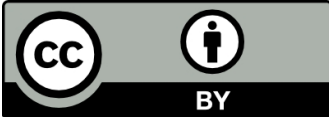

Submit your manuscript to Boston science publishing journal and benifit from:

- Convenient online submission

Rigorous peer review

- Immediate publication on acceptance

Open access: articles freely available online

High visibility within the field

- Retaining the copyright to your article

Submit your manuscript at $\ddagger$ bostonsciencepublishing.us $\ddagger$ 